\title{
FUNCTIONAL VOMITING IN NEWBORN AND PREMATURE INFANTS.
}

BY

\author{
WILLIAM EMDIN, B.A., M.D.
}

In making a study of the symptom of vomiting in the newborn and premature infant, the descriptions here mentioned and the conclusions drawn are based on observations made in the wards of the Universitäts Kinderklinik and the Maternity Wards of the Peham Frauenklinik at Vienna. Pirquet has instituted a method of recording by means of symbols the exact description of the act of vomiting so that the case sheets give details of the progress of the case in this direction, thus facilitating the study of the cases.

\section{Anatomy and Physiology in connection with the Act of Vomiting.}

The investigation of the infantile stomach by means of X-rays has opened up a hitherto undefined field, viz., that of the anatomy and physiology of the stomach during life. The form and position of the stomach is very similar to that of the adult, except that, as recent investigations seem to show, the position is usually horizontal rather than vertical. We can distinguish five parts ; the fundus, body, pars angularis, canalis pylori (or pyloric antrum) and the pyloric valve.

The œsophagus runs downwards, forwards and to the left to meet the stomach. Thus gruels and the more solid foods are given a propulsion towards the fundus, whereas fluids pass along the so-called gastric canal of Lewis ${ }^{10}$ ('Waldeyerische Magenstrasse '), an anatomical landmark which was demonstrated by Lewis on the stomach wall of the human embryo, running along the lesser curvature from the antrum cardiacum to the incisura angularis. The lesser curvature is directed dorsally in the infant. Milk passes from the cardia to the pylorus and thence to the duodenum without entering the fundus ventriculi. The upper part of the œsophagus contains voluntary muscle which passes also, to some extent, into the lower portion. There is no evidence of the presence of striated muscle at the cardiac sphincter : that is to say, there is no voluntary control at this area.

The radiographic appearance of the stomach varies with the type of food ingested. When the content is fluid, an oval, pear-shaped or even " bagpipe " contour may be noted. This depends to some extent also on the amount of air swallowed, which is often in considerable quantity when the diet is a fluid one. When gruels have been taken, the infantile gastric organ is contracted, circular or oval in shape, and barely reaches the mid-line. It contains 
perhaps a small air bubble, or as is frequently the case, no air at all (Rogatz ${ }^{14}$ ). Various observers have shown that the 'peristolic function' which the stomach has of contracting down upon food occurs in infants as well as in adults, especially when the more solid foods, i.e., gruels, have been ingested. Solid food, therefore, has two distinct advantages when used as a therapeutic measure in the inhibition of vomiting ; first, the food is surrounded by the contracting stomach wall, thus hindering loss by emesis; and secondly, little air is swallowed in the process of ingestion.

The pyloric antrum ("Magenmotor" or canalis pylori of Müller) is of interest because it is in this area that the pressing out movements of the stomach originate, as do also the spastic and anatomical alterations which accompany pyloric stenosis (Wernstedt"19). This has been termed the "contraction phenomenon area" because it is here that hour-glass contractions are seen by means of $\mathrm{X}$-rays in the perfectly normal infant.

Swallowed food, chiefly milk in infancy, having entered the stomach, peristaltic waves which originate superficially about the middle of the stomach $\left(\right.$ Cannon $\left.^{2}\right)$ and from the greater curvature (Theile ${ }^{18}$ ) pass towards the pylorus, penetrating deeper and deeper, and resulting in the complete closure of the lumen of the pyloric antrum which subsequently commences to contract. The pyloric valve then opens. Marked motor activity on the part of the stomach has evidently some effect on the opening of this sphincter and thus hyperacidity cannot be the only factor concerned in this process. The ingested milk is thus thoroughly mixed with, and rapidly acted upon by, the gastric juices. Curd formation owing to the action of rennin takes place, thus affording proof that the milk has actually reached the stomach.

$\mathrm{X}$-ray investigation shows that a bismuth meal begins to leave the stomach within five minutes of entrance, the total emptying time being from $1 \frac{1}{2}$ to 3 hours (Pisek and Lewald ${ }^{12}$ ). Milk dilution increases the rapidity of evacuation to a certain degree only; solid food on the other hand is passed into the duodenum with a rapidity varying inversely with the degree of concentration. An increase in the fat content lengthens the emptying time. As a result of recent investigation, Rosenbaum ${ }^{15}$ believes that protein is an important factor in inhibiting pyloric opening, and he maintains that the relatively higher protein content of cow's milk as compared with that of human milk is the chief cause of the slower digestion of the former.

With regard to hunger movements, Carlson ${ }^{3}$ states from observations on the stomach of newborn and premature infants that such movements are present as in the adult, but are of greater frequency and relatively greater vigour. They commence at the cardia. His work has been confirmed by Taylor. ${ }^{17}$

\section{Vomiting In the Newborn Infant.}

Before entering on a consideration of vomiting in the newborn infant it is necessary to mention that vomiting not associated with nutritional, 
bodily or neurotic disturbance may occur one or more times during the first day or so of life. This consists in the return of foreign substances swallowed during the birth period. The vomitus, which is usually a colourless, slimy fluid containing perhaps brown, hæmorrhagic masses incorporated in it, may be copious in amount and consist of liquor amnii, vaginal secretion, swallowed blood, etc. (Reuss ${ }^{13}$ ).

With the commencement of food assimilation, vomiting is an extremely common occurrence. Various factors are concerned in its causation. A breast which too readily yields its secretion may lead to over-feeding and the excess of milk is returned, usually immediately. Swallowed air when eructated may bring with it some of the milk, or, interference with the breathing may be the cause, as occurs when the mother presses the child too forcibly against the breast, thus occluding the nostrils and necessitating the interruption of feeding in order that the infant may breathe. Congenitally narrow nostrils or nasal catarrh may have the same effect, and this break in the feeding is very often accompanied by the regurgitation of milk from the baby's mouth. A fair quantity of the food may be lost in this way.

Apart from this, however, vomiting which cannot be attributed to the above causes on the one hand or infections on the other, occurs with a frequency which is striking. On observing the newborn infant at the breast, it may be noticed that at times there is a cessation of suction and milk is seen to well up in the mouth of the infant and overflow the lip margins. There is no force behind this flowing milk, nor are curds present. This manifestation is not correctly included under the term infantile vomiting, because the milk has never reached the stomach. The most probable explanation (Pirquet) is that in the newly born infant there is a lack of co-ordination between the muscles concerned in the act of swallowing, and the child has not yet learned to swallow properly. This art is, however, rapidly acquired. To this type I would apply the term "pseudo-vomiting" in contradistinction to true vomiting of the milk which has actually reached the stomach.

Apart from this pseudo-vomiting there is no doubt that actual vomiting occurs with relative frequency during the early period of infancy. Schick ${ }^{16}$, while studying the effect of various forms of nutrition on the newborn infant was struck by the frequency with which vomiting became manifest. Even when a concentrated food was given ("Dubo" or doubly concentrated food) he noticed that vomiting occurred in cases where overfeeding was out of the question, as the food intake had been carefully determined. Nor could the type of food given have been the causative agent because when the mother's milk was given in small quantities, or even when the milk was replaced by small amounts of saccharine-sweetened tea, vomiting still occurred. We have then, at this period, not only pseudo-vomiting, but also true vomiting, the infant being unaffected at the time or later, i.e., no harmful effects follow.

I commenced the study of vomiting in the newborn infant by investigating three hundred consecutive cases during the first week of life. Of these, if we consider both the true and pseudo-vomiters, about 55 per cent. of the total 
number returned the milk. In order to study true vomiters during the first days of life pseudo-vomiters were disregarded and only those infants considered whose vomit contained curdled milk, or was of such amount and frequency as to make it clear that the milk had actually been in the stomach. It should be remembered that it is possible for the milk to have been swallowed and then vomited before the rennin has been able to produce a curd.

The following were the results obtained :-

1. Excluding pseudo-vomiters, of which there was a good number, 64 of the 300 were true vomiters, a percentage of $21 \cdot 3$.

2. Of these 64 cases, 36 were male and 28 female infants. The total number of male and female children being 161 and 139 respectively, gives a percentage of 22.4 male and 20.2 female vomiters, which shows no special sex tendency towards vomiting.

3. With regard to the relation of body weight to vomiting, of the above mentioned 64 vomiters, 14 were born with a body weight below that of 2,500 grammes (5 lb. $8 \mathrm{oz}$.) and of the total 300 cases, 39 were below this weight at birth so that the percentage of vomiters below 2,500 grammes birth weight rises to 36. When we compare this figure with the percentage figure of infant vomiters above 2,500 grammes weight at birth (50 out of 261 or $19.2 \%$ ) a more pronounced tendency towards vomiting is demonstrated on the part of the premature and weak infants even during the first week of life.

4. Vomiting usually commences about the end of the first day or on the second day of life, i.e., when milk is first assimilated. This type of vomiting is purely physiological in character in that it produces no ill effects on the infant. There is probably some relation between this and the drop in the weight curve which takes place during the first days of life, but the vomiting is not the essential cause of this drop, because a similar temporary loss in weight occurs in infants who vomit little or even not at all.

5. The vomiting increases in frequency during the second and third days, and perhaps the fourth day of life, after which, in most cases, it rapidly decreases in frequency and amount, so that by the sixth or seventh day very few infants vomit much. The vomit is composed of milk in which curds may be seen, and it may be ejected from the mouth with a slight amount of force and is often found lying on the bedclothes a little distance from the infant. Usually, however, there is little force behind the act. Pseudo-vomiting, on the other hand, is more common during the first two or three days, is always flowing in character and disappears towards the end of the week as the infant acquires control over the muscles concerned in the act of swallowing.

6. Vomiting may occur in infants of excellent bodily development without being followed by harmful effects. In nine of the cases under consideration the minimum weight was $3,300 \mathrm{grm}$. (about $7 \frac{1}{2} \mathrm{lb}$.) and the maximum 4,000

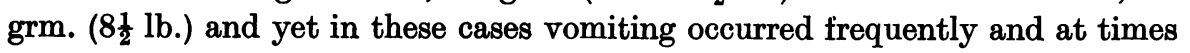
fairly copiously. It is interesting to note that in two of them bile appeared in the vomit without being of any special significance, although this occurred 
during the first days of life. There was no subsequent evidence to prove that the infants were at all affected by the appearance of this abnormal substance in the vomitus ; in fact, there was not even an accompanying loss in weight, the infants developing normally and rapidly.

The subsequent history of these cases was difficult to determine for the reason that being normal children they soon left the clinic and the observations of the mother with regard to vomiting are insufficiently reliable. A study of case records goes to show that most normal infants cease vomiting, except for periodic bouts of short duration, by the end of the first week. Vomiting may continue in perfectly normal infants for two, three, or even more weeks without being pathological ; in fact, if unaccompanied by harmful signs, such as loss in weight, this manifestation may be totally disregarded. Such cases are, however, comparatively uncommon, and as a general rule obstinate viomiting continuing for a longer period than the first week should be looked upon with suspicion and the possibility of habit developing should be kept in mind: that is, if all other possible causes, such as organic disease, can be excluded.

\section{Vomiting in the Premature Infant.}

Under "Prematures and Weaklings" are included those infants with a birth weight of less than 2,500 grm. ( $5 \frac{1}{2} \mathrm{lb}$.). A few facts in connection with vomiting in the immature infant are of importance. The stomach of the premature infant is extremely small, its capacity in an infant weighing at birth 1,000 grm. (about $2 \mathrm{lb}$.), being not more than five cubic centimetres and often as little as two. Further, the closure mechanism of the cardiac sphincter is poorly developed, in fact a sound can be readily passed without much resistance being encountered. Thus food is easily able to leave the cardiac end of the stomach. The infantile mortality of the premature and weakling is extremely high, being due among other factors to the frequency of the complication, pneumonia, the irregularity of thermo-regulation, etc., the mortality increasing by leaps and bounds in inverse ratio to the body weight. Thus the mortality of prematures under 1,000 grm. weight at birth is, during the first year of life, as high as $94 \cdot 4$ per cent. whereas the average mortality for all prematures during the first year is about 50 per cent. (Ylppö ${ }^{21}$ ).

In all, a study was made of some sixty cases of premature and weakly infants. At the Universitäts Kinderklinik at Vienna, the dietetic method of treating premature infants is to give a concentrated food of small bulk. Milk to which $12 \frac{1}{2}$ per cent. sugar is added (so-called "Sesquibo") is commonly used. Cow's milk, or better, human milk is given to the infant. Where necessary doubly concentrated human or cow's milk may be used. This double concentration is obtained by the addition of 17 per cent. sugar, thus giving a double caloric value to the mixture. For example, cow's milk has a caloric value of 67 to the $100 \mathrm{grm}$. ( $3 \frac{1}{2} \mathrm{oz}$.). If we add to this, $17 \mathrm{grm}$. of sugar (67 calories) we have a mixture when boiled weighing roughly $100 \mathrm{grm}$. and containing 134 calories, a double concentration (the so-called "Dubo"). In very small and 
delicate infants a commencement is made with small and frequent feeds of unaltered mother's milk. Naturally, no hard and fast rule can be laid down to cover every contingency, and the above is but a résumé of the general principles which are applied.

On studying premature and weakly infants, I found it was possible to divide them, as in those of normal weight, into distinct groups, the vomiters and the non- (or slight) vomiters. The vomiters were further subdivided into those which died and the survivors.

To commence then with those infants which survived. Of a con. secutive series of thirty-two cases which came under my consideration, only twelve survived. Most of the survivors vomited frequently during the first two weeks of life, ceasing, with two exceptions which continued vomiting up to and including the second month, by the third week. The study of other cases of prematurity has shown that many infants, perfectly healthy, with good stools and no sign of infection, gaining weight steadily, have vomited consistently for a long period, even up to and including the third or fourth month. The following is a typical example of such a premature vomiter :-

CASE 1. G.T. Weight at birth 1,600 grm. Fed on Sesquibo and showed a steady gain in weight from the commencement. No nutritional or general disturbance of any kind, and yet the infant vomited continually 3 to 5 times daily, often with some force. The infant was still vomiting at the end of the first month.

All premature infants do not necessarily vomit. Of the twelve cases mentioned, only three vomited for a period longer than two weeks, two continuing into the second month. The percentage of vomiters is far higher than among children weighing 3,000 or more grm. at birth; thus the premature infant seems to have a greater tendency towards vomiting than his more fortunate brother.

To state that weight is the only important factor is an exaggeration. The birth weights of the twelve survivors were: 1,740, 1,700, 2,010, 1,720, $1,800,1,200,1,500,1,800,2,200,1,800,1,760$ and 2,100 grm. respectively, nine of the twelve weighing less than 2,000 grm. $\left(4 \frac{1}{4} \mathrm{lb}\right.$.). We know that the smaller the birth weight the greater the tendency towards vomiting, infection and death. The above cases show, however, that weight is not the only deciding factor with regard to survival. In my opinion, at least two important accessories which in the premature infant are often lacking, are, a sufficient constitutional development to enable the weakling, however small, to withstand the attacks of infection, and, what is essentially influenced by the above, a sufficient inhibitory control of vomiting. I am assuming, of course, that the infant has received reasonable and intelligent care and has not been unduly exposed to infection, as is often the case owing to ignorance. The question of inhibitory control which in the premature infant is often defective, will be discussed more fully when the possible ætiology of vomiting in the newborn is considered. It might be argued that the premature infant is prone to infection (hence the high mortality), which of itself is the cause of vomiting. Although this may be true to some extent, another possibility might be con- 
sidered, viz., that the premature infant, owing to its tendency to vomit, loses food and thus is further weakened. This still further lowers its congenitally insufficient resistance and vitality, a vicious cycle being established.

The survivors may, then, be vomiters or non-vomiters. In connection with the non-vomiters it must not be forgotten that this type of infant at this clinic is fed on a concentrated diet which in itself ought to act to some extent as a deterrent from emesis. With regard to the second group of survivors, viz., those which vomit for a long period in spite of the fact that they are receiving a concentrated diet, and which thrive in spite of this if properly looked after and given sufficient to cover the food loss, it is possible that even in a well developed constitution the inhibitory control, at first insufficient, subsequently leads to the development of a habit. In other words, this infant may be likened to the habitual or neurotic type of vomiter with a higher birth weight.

The act of vomiting in premature infants is rarely forcible. As a rule it starts to vomit more slowly than the normally developed child, but soon begins, if a vomiter, to vomit more frequently, obstinately and copiously, especially when a complication, whether gastro-intestinal or otherwise, is present. We often find included in the vomitus of the premature infant adventitious substances such as mucus, blood, and bile. During the first few days of life the gastric mucous membrane of the weakling is frequently covered by an abundant layer of mucous secretion, and many of the infants have a mucous membrane impregnated with blood. It is often possible to discover post mortem minute multiple ulcers in the mucous membrane, and these ulcers are held to be an important source of entry of sepsis and infectioncausing bacteria.

The non-surviving premature infants, most of whom vomit, commence vomiting infrequently, but gradually begin to vomit more often. The following is a description of a typical example. The infant died on the ninth day of life and showed so many features in connection with the vomiting of the moribund weakling that it will be considered in detail.

CASE 2. F.R. Born on November 2nd, 1926, weighing 1,150 grm. (about 2 lb. 6 oz.). Icterus was a prominent feature and deepened as time progressed. The infant was placed in an incubator and fed on human milk, at first receiving $64 \mathrm{c.cm}$. per day and later $120 \mathrm{c.cm}$. Owing to feeble sucking it was necessary to feed the child by means of a tube. The vomiting was actual vomiting, but small in amount at first. As early as the second day the presence of bile in the vomit was noted. On the fifth day, the infant vomited several times, bile appeared on two occasions, and the character of the vomiting act altered. Where before it had been of a flowing nature, it now became forcible and more frequent owing probably to the grip of a pneumonic infection. Then the forcible vomiting gave place to a more placid type, due possibly to exhaustion and the defeat of the bodily resistance. With the progress of the case bile again appeared in the vomit, which contained also mucus, bus: the act was no longer forcible, but flowing in character. Finally the child died, death being preceded by vomiting of a flowing nature, the vomitus containing traces of blood as brownish-red streaks.

One point of especial interest was observed in connection with this infant, namely that the child vomited through the nose. This occurred twice and on both occasions bile was contained in the vomit, small in quantity the first time when the vomit was slightly projectile in character, 
but more copious on the second occasion, which took place shortly before death. The latter type is the more common and $I$ have known it to occur with relative frequency in moribund premature infants. One usually notices that the bile-stained fluid flows out of the nostrils and also the mouth just before death, and this manifestation is, in my opinion, of extremely grave prog. nostic significance.

The post-mortem examination showed a lobular pneumonia, physical signs of which were present before death. The temperature curve was interesting in that there was no pyrexia present in spite of the critical condition of the child. This is a common finding where premature infants are concerned. On the eighth day a drop in temperature to 33 degrees Centigrade (91 degrees F.) was noted, and on the day of death, the temperature rose to just above normal. Just before death, also, a small amount of blood appeared in the vomit, a manifestation which $I$ have noted in some six other moribund premature infants.

The case presents so typical a picture that it is unnecessary to go further into detail except to note the increasing frequency of the vomiting, the alteration in character, the presence of abnormal accessory substances in the vomited matter, and the flow of the bile-stained vomit through the nose: Finally, the type of vomiting in association with the presence of bile is worthy of note. (1) On the second day of life, a small amount of bile-stained fluid was vomited, unmixed with milk; (2) on the fifth day, the act was forcible in character and the vomit contained mucus, bile and also milk ; (3) on the day of death, there was non-forcible flowing vomiting, the vomitus being more copious than previously and containing mucus, bile and milk.

The above illustrates many of the typical findings in moribund premature infants. Several other cases showed similar findings, but it is unnecessary to quote them as they would be more or less a recapitulation of the above.

\section{The Significance of Bile and Blood in the Vomit.}

We have seen that the appearance of bile in the vomit during the first few days of life is important, especially where the premature infant is concerned, but not necessarily of grave prognostic significance. Referring to the nine normal infants considered in the second section, it was noted that bile appeared in the vomit of two, unaccompanied by any harmful symptoms whatsoever. Further, it was found that in both these cases the amount vomited was small and the vomited matter contained no milk, being composed purely of a mixture of bile and gastric secretion. It is worthy of note, also, that Case 2, where the vomit contained bile on three occasions, showed this same feature on the first occasion when probably still in the non-infected stage, viz., the bile was unmixed with milk. This might lead to the conclusion that the momentary relaxation of the pyloric sphincter and the regurgitation of some bile into the empty stomach is less pathological than when the stomach contains food, because in the latter case the bile must be forced against the pressure of the stomach contents.

Many authors attach the gravest significance to the presence of bile in the vomit, especially in earliest infancy. Langstein ${ }^{8}$ advises that these newborn infants be treated as though having severe nutritional disturbance. With regard to premature infants there is no doubt as to the importance of this sign, especially when copious vomiting occurs. In hitherto normal infants, if the vomiting is not too copious and of infrequent occurrence, especially if there is no coincident loss of weight, little significance may be attached to it. These conclusions were arrived at after a study of a number of cases and case records, 
Copious biliary vomiting, then, is a valuable guide to prognosis in early infancy, and its causation of great importance. A common cause of this type of bilious vomiting is found in congenital defects of the intestinal tract. The following was such a case and from the differential diagnostic point of view wai interesting :-

Case 3. M.H. Mongol. Premature infant with congenital heart lesion. Vomited from birth and only lived two days. Analysis of the vomiting was as follows :-

1st day. Infant vomited eleven times. Bile was copious in amount and for the most part the vomiting act was projectile in character.

2nd day. Child vomited nine times and then died. On this day, the vomit was non-projectile. Post-mortem examination showed an atresia of the duodeno-jejunal junction.

Bilious vomiting is also found where a temporary atresia has occurred, as for example in intussusception.

The following case demonstrates the fact that biliary vomiting may occur copiously and frequently where there is no organic lesion and thus probably has some nervous influence as the cause.

CASE 4. M.V. A premature infant with a birth weight of $3 \frac{1}{4}$ lb. Vomited copious bilecontaining fluid from the first day of life. Infant had difficulty in breathing from birth and ultimately on the fourth day respiratory cessation occurred and the child died. Post-mortem examination showed a ruptured tentorium cerebelli with severe epi- and sub-tentorial hæmorrhage.

lst day. Child vomited seven times and on four occasions bile was present in fairly large amounts.

2nd day. Child vomited fourteen times and on six of these occasions the vomited matter contained bile, and was forcibly ejected.

3rd day. Child vomited twelve times, mostly projectile, and bile was found in the vomit each time.

4th day. The child died, after vomiting eight times, bile being present in nearly every specimen of the vomitus.

In this case the causative agent was irritative impulses from the central nervous system and the marked effect of cerebral control in so under-developed an infant is interesting. Here the vomiting act was decisive in character and forcible from the start with the early and persistent appearance of bile in the vomit.

A comparison of this case with Case 3 in which there was an organic gastro-intestinal malformation shows the power of cerebral control, even in an under-developed and immature infant.

Considering now vomiting in relation to icterus, icterus occurs in infancy in the following conditions : (1) Icterus neonatorum ; (2) Icterus neonatorum gravis ; (3) Symptomatic icterus, as in acute infections, sepsis neonatorum, etc. ; (4) Congenital syphilis ; (5) Congenital atresia and narrowing of the large bile ducts.

Icterus is also an accompanying manifestation in premature infants. Most of the above mentioned do not come under the heading of functional conditions. I have seen one case of congenital atresia of the common bile duct, but as would be expected, no bile appeared in the vomit. Unfortunately no case of Icterus neonaturum gravis presented itself, and with regard to congenital syphilis, I would only remark that in several cases vomiting of bilecontaining material occurred. In a series of cases of Icterus neonatorum, I 
found nothing of special importance with regard to vomiting, as might be expected in a physiological condition of such benignity. Once or twice bile appeared in the vomit, but it is not a constant feature and is probably similar in origin to the bile present in the vomit of the healthy infant.

How may we recognize the presence of bile in the vomit? This is not always easy. The colour varies, with the concentration of the bile and the medium in which it lies, from a light yellow to a dark green. Further, it may be diffused throughout the vomited substance or present as light yellow dots of varying size. If the vomit is diffusely bile-stained and contains cow's milk, the bile may tinge the milk a light yellow colour so that the appearance is that of colostrum milk, and as the majority of the newborn infants arebreast fed and thus receive at first the colostrum-rich breast-milk which has a yellowish tinge, the latter, if vomited, must not be confused with bile-containing vomit. On the other hand, the milk may be spotted with chrome yellow dots, or, if in greater concentration, greenish masses, which might easily be confused with the greenish mucus produced by nasal catarrh which has been swallowed and vomited. The distinction is not always easy and chemical examination may be necessary in order to be certain. Where the bile is mixed with gastric juice alone, i.e., in the absence of milk, the colour is usually of a darker green and diffused throughout the fluid.

Blood also, when present, may be diffused throughout the vomited fluid, which is then of a light red colour. This is uncommon during infancy except where melæna neonatorum is present. It may appear as dark brownish shreds ("coffee-ground" vomiting) or even as small brownish masses. Hæmatin, which is the substance present in these latter types, is formed by the action of the hydrochloric acid of the gastric juice on the hæmoglobin.

Newborn and premature infants show a definite tendency toward hæmatemesis as well as to other forms of bleeding. At no other period of life is hæmorrhage into the skin, internal organs and mucous membranes so prevalent (Langstein and Lotte Lande ${ }^{9}$ ). This does not fall under the heading of the hæmorrhagic diathesis (Ylppö:0), but the following factors have probably some relation to bleeding during the early days of life :-

(a) Birth is accompanied by the congestion of the blood vessels and this is especially marked when there is an associated asphyxia. The higher viscosity and specific gravity of the blood at this period are probably aggravating factors.

(b) The blood vessels are easily damaged.

(c) Icterus, a common manifestation in newborn, and always present in premature infants, has a coagulation-inhibiting tendency.

Premature infants show a tendency towards hæmatemesis, as in Case 2, mentioned previously, where blood was vomited just before death. In six other moribund premature infants I found blood in the vomit.

The following three cases were infants suffering from melæna neonatorum, It is worthy of note that all three were premature infants. 
CASE 5. H.K. Born on August 4th, 1926. Weight $4 \frac{1}{4}$ lb. On the first day of life the child had many bloody stools, but no blood in the vomit. Gelatin was injected intramuscularly as a therapeutic measure, and blood ceased appearing in the stools after the third day. No blood appeared in the vomit ; but the child showed itself to be a bad sucker and actual vomiter from birth. The vomiting became habitual ( 3 to 5 times daily) although not projectile. Appetite and stools good. Bile appeared in the vomit twice with apparently no ill effects. At the end of the second month the child was still vomiting, although little, and this ceased entirely soon after.

Case 6. F.B. Two days old. Weight at birth under $5 \mathrm{lb}$. Vomited blood (red) on the third day of life and then once daily until the infant was seven days old. The infant soon showed itself to be a persistent vomiter, vomiting 4 to 6 times daily, chiefly non-spastic in nature. A doubly concentrated diet of cow's milk and, when obtainable, mother's milk, was given, and the infant began to vomit less frequently. After six weeks of treatment the habit was broken. During the first two weeks the vomiting was forcible in nature, but later became more atonic. The vomited matter contained curdled milk and sometimes mucus.

CASE 7. J.S. Birth weight $4 \mathrm{lb} .6 \mathrm{oz}$. When 18 hours old the infant vomited bloody fluid which was of a light red colour and contained coffee-coloured masses. Nothing pathological in the mouth or throat was visible. With treatment the child vomited blood only once more. In this case, there was the development of habitual vomiting, often of a spastic nature, six or seven times daily. After the fourth week, with the use of a concentrated diet, the vomiting became less forcible in character, and in the sixth and seventh weeks there was a marked change for the better.

The above cases illustrate the point that there seems to be a tendency towards vomiting where melæna is present. Whether the presence of melæna has some effect in furthering the vomiting habit is open to conjecture, but as this condition commonly occurs in premature infants, who also show a greater tendency to vomit than infants with a higher birth weight, the immaturity may have some effect in this direction, aggravated perhaps by the melæna.

The origin of true melæna is still unknown. Associated with this condition we often find multiple small ulcers of the stomach and duodenum, and perhaps ulceration of other parts of the alimentary tract. These may, however, be entirely absent, and at the post-mortem examination a diffuse hæmorrhage, or a hyperæmia of the mucous membranes, may often be found. The presence of the ulcers might be explained in a number of ways. The action of the gastric juices on the physiologically hyperæmic areas, or punctate bleedings of the mucous membranes producing erosions and peptic ulcers which in turn erode into larger vessels and thus give rise to further hæmorrhage. Again, hæmorrhage and tissue digestion following thrombosis of the small intestinal vessels, resulting from vasomotor ischæmia, might give rise to such ulcers. There is a theory also that conditions of severe central nervous irritation may cause hæmorrhages of the intestinal mucosa, the action of the gastric juice producing ulceration. Finally, we know that the vessels of the newborn infant are fragile and may thus be readily induced to bleed by toxins either bacterial or non-bacterial (toxins of pregnancy or those produced by a damaged or an inefficiently acting liver).

\section{V.-Atiology of Vomiting in Newborn and Premature Infants.}

We know that the act of vomiting in the adult is a complicated one, and is difficult to explain. First there are nausea and salivation followed by 
depression of the diaphragm upon the stomach, which increases the negative pressure in the thorax and œsophagus. The fundus ventriculi relaxes, peristaltic movements in the region of the antrum cease; the pylorus contracts; the fundus becomes filled with stomach contents, the cardia opens, and under the influence of diaphragmatic pressure reinforced by a convulsive contraction of the abdominal musculature, the stomach muscles contract and the stomach contents are projected into the œsophagus and the mouth, assisted by negative pressure. Whether anti-peristalsis plays an important part in this phenomenon is still a matter of controversy.

How then is this highly complex mechanism set in motion? If we consult the literature, much of interest both experimental and theoretical may be found. Giannuzzi ${ }^{5}$, many years ago, showed that an animal poisoned with curare did not react to an emetic by vomiting, presumably because the abdominal muscles were paralysed. That the diaphragm is also important is shown by the fact that section of the phrenic nerves in animals has an inhibiting action on the occurrence of emesis ; in fact, if the abdominal muscles are at the same time prevented from contracting, the act of vomiting may be entirely suppressed.

Muscular action alone cannot be the sole factor responsible because it has been shown that in spite of intensive muscular pressure, vomiting does not occur when the cardiac sphincter is closed. That an actual sphincter exists at the junction of the osophagus and stomach is believed by Poulton, Payne, Hurst $^{6}$ and others. This sphincter remains closed after a meal and prevents regurgitation of food, gases and gastric juices, which would otherwise occur owing to the gastric pressure associated with the negative thoracic pressure. If this pressure is suddenly raised, the sphincteric resistance is overcome and the cardia opens.

Another important point is the question of nervous control of the stomach. The autonomic intrinsic nerve plexuses of the stomach are under the control of the vagi (chiefly motor in function) and the sympathetics (chiefly inhibitory). Both these nerve trunks seem capable of carrying impulses necessary to start the act of vomiting, and in one and the same animal the same poison may give rise to vomiting by way of different nerve paths. Hatcher and Weiss" found that the use of medium doses of digitalis caused vomiting by way of the vagus, whereas strophanthin gave the same result through the splanchnics. The vagus, however, seems to be the chief path by way of which vomitingpromoting impulses are carried. Klee ${ }^{7}$ demonstrated that stimulation of the undivided vagus was followed by pyloric closure, opening of the cardia and vomiting. Without going into further detail, it may be stated that more recent experimental evidence points to the fact that the closure of the pyloric valve is chiefly under splanchnic control, whereas the vagi influence the opening of the cardiac sphincter.

In considering the problem of the possible ætiology of true vomiting in the infant, the first point of importance is that the vomiting act differs somewhat from that of the adult. For example, the pressure of the abdominal musculature plays a very small part, and vomiting seems to be a far less unpleasant process, and one more easily initiated than in the adult. There 
appears to be little evidence of any accompanying nausea. Atony of the stomach, however, is commonly present and this is perhaps an important predisposing factor to the ease with which vomiting occurs in the infant (Lindberg ${ }^{11}$ ).

$\mathrm{X}$-ray and clinical investigation show a tendency towards relaxation on the part of the cardiac sphincter in the newborn infant, and this is especially marked in premature and weakly infants. This deficient sphincteric closure is probably associated with atony of the gastric musculature and it is easily demonstrable that after a meal only a slight pressure over the infant's abdomen is necessary in order to cause vomiting. In cases where an infant vomits directly after a meal, the causative agent may be so slight as a contraction of the pyloric antrum unassisted by muscular pressure (Reuss ${ }^{13}$ ).

Many authors hold that associated with this insufficiency of sphincteric tone there is present a hypersensibility of the gastric mucous membrane. It is worthy of note in this connection that although this is a possible explanation of the vomiting of the neurotic infant, it must not be forgotten that quite a number of normal infants vomit, but rapidly lose this tendency. Another view is that there may be a hypersensitivity towards food to begin with, but as the stomach becomes accustomed to food by repeated fillings, this sensitivity disappears, i.e., a full stomach is therefore a good prophylactic against vomiting $\left(\right.$ Schick $\left.^{16}\right)$.

The theory that the first fillings of the stomach cause reflex, perhaps anti-peristaltic, contractions of the stomach musculature and thus lead to vomiting, has been advanced, but that anti-peristalsis is a cause of vomiting in the newborn infant is open to doubt. Hess in his experiments was unable to demonstrate it. More recently other observers who were studying vomiting as a result of apomorphine poisoning, noticed that anti-peristaltic waves were visible under X-ray examination. During the process of radiographing an infant with pyloric stenosis, Dr. H. Wimberger, Radiologist to the Pirquet Clinic, and I noted definite anti-peristaltic waves. This was immediately followed by some of the barium feed being shot up into the œsophagus and then slowly sinking back into the stomach : no vomiting occurred.

Unfortunately, the method of investigating vomiting in infants by means of X-rays has its limitations, for it is impossible to subject an infant to the rays for sufficiently long to observe the natural act of vomiting. Especially does this obtain so far as the newborn infant is concerned, because the danger of X-ray injury increases inversely with the age of the child. Again in the case of an infant vomiter, even if one is fortunate enough to witness spontaneous vomiting, the observations are of little value owing to the rapidity with which the act takes place, and the little likelihood of repetition. If we observe, for example, an infant with pyloric stenosis during one of its vomiting bouts, we note that the vomitus is suddenly, rapidly and forcibly ejected. Radiologically we obtain a corresponding picture. The stomach suddenly contracts, too rapidly to allow details to be apparent, and all is over. Such investigatory methods in living infants are, therefore, liable to be difficult and unsatisfactory. 
With regard to the nerves influencing the stomach, although the influence of vagi and sympathetics is complicated, we may take it that the vagus is chiefly motor in its action, and the sympathetics inhibitory. H. C. Cameron ${ }^{1}$ puts forward the hypothesis that vomiting in the newborn period is facilitated by the absence of a sufficient inhibitory influence. He states that there are several indications pointing to the fact that in earliest infancy the inhibitory activities of the sympathetic are weak and that in the newborn infant, when a large part of the cerebrum is functionless, there may be at times added to lack of inhibition of skeletal musculature a similar weakness of power to inhibit the splanchnic musculature. After all, inhibition, the highest function, is late in development and it seems to be logical to suppose that in the newborn infant such inhibition may be insufficiently developed.

This leads me to the following conclusion as to the possible ætiology of vomiting in the new-born infant :-

The sympathetic system being insufficiently developed, the nervous action in the newborn infant is chiefly vagal with the result that there is a vagotonia. In support of this there is sufficient evidence. This results in a tendency towards increased movements of the gut and, therefore, a tendency towards vomiting. Stimulation of the vagus is followed by relaxation of the cardiac sphincter according to recent investigations, therefore an inhibited vagal action would account for the atony of the sphincter ; and that this atony is important in this connection I am convinced. Compare the ease and comparative, sometimes actual, pleasure with which the infant vomits with the nausea and retching which the adult is compelled to experience in the same act. In the adult a period of nausea is followed by violent contractions of the abdominal musculature with contraction of the diaphragm in order that the act may be completed. To my mind the chief obstacle which the adult stomach has to overcome is the closed cardiac sphincter; whereas in the infant, owing to insufficiently developed sphincteric control, the cardiac sphincter is readily overcome and vomiting easily occurs.

Carrying this line of explanation further, within the first week of life most normal infants develop sufficient inhibitory (sympathetic) control to stop their tendency to vomit. Premature infants and weaklings require still more time in order to develop this inhibition to a sufficient degree, and the smaller the infant themore time required, and the more difficult the achievement, owing to the facility with which infection takes a grip on an organism weakened congenitally and still further weakened by food loss. Weight is not the only factor concerned, because a premature infant born with comparative constitutional strength which embodies a certain amount of inhibitory control, will more readily tend to survive. Or vice versa, a child of normal birth weight with insufficient or slowly developing inhibitory control will go on vomiting for a longer period than its better equipped brother, and thus lays itself open to the acquisition of habit. Nor is it a long step from such vomiting, if untreated and especially if of a neurotic character, to habitual vomiting. 


\section{REFERENCES.}

1. Cameron, H. C., Brit. Med. J., Lond., 1925, i, 765, 815, 872.

2. Cannon, W. B., Amer. J. Med. Sc., Philad., 1906, CXXXI, 563.

3. Carlson and Guinsberg, Amer. J. Physiol, Baltimore, 1913, XXXVIII, 29.

4. Hatcher and Weiss, Openchowsky, Thomas, mentioned in Ueber das Erbrechen (Pineles).

5. Howell, Physiology, 1924, 738 et seq.

6. Hurst, A. F., Brit. Med. J., Lond., 1925, i, 145.

7. Klee, Arch.f. d. ges. Physiol., Berlin, 1912, CXLV, 557.

8. Langstein and Goeppert, Prophylaxe und Therap. der Kinderkrankheiten, 1920, 96.

9. Langstein and Lotte Lande, Kinderheilkunde, Pfaundler and Schlossmann, 1923, I,488, 534

10. Lewis, Amer. J. of Anat., Philad., XIII.

11. Lindberg, Amer. J. Dis. Child., Chicago, 1924, XXVII, 197.

12. Pisek and Lewald, Amer. J. Dis. Child., Chicago, 1913, VI, 232.

13. Reuss, Die Krankheiten des Neugeborenen, Berlin, 1914.

14. Rogatz, Amer. J. Dis. Child., Chicago, 1924, XXVIII, 69.

15. Rosenbaum, Phys. and Path. des Sauglingsmagens, Berlin, 1925.

16. Schick, B., Ztschr. f. Kinderh., Berlin, 1917, XVIII, Heft., $1 / 2$.

17. Taylor, R., Amer. J. Dis. Child., Chicago, 1917, XIV, 258.

18. Theile, Ztschr.f. Kinderh., Berlin, 1917, XV, 152.

19. Wernstedt, Arch.f. Anat. \& Phys. Anat. Abtlg. Sp., 1913, 97.

20. Ylppö, Kinderheilkunde, Pfaundler and Schlossmann, I, 549.

21. Ylppö, Ztschr.f. Kinderh., Berlin, 1919 XX, 212. 